\title{
Lyme Meningitis in Children with Acute Serous Meningitis with no Clinical Signs of Lyme Borreliosis at Presentation
}

\author{
Mojca Rozic ${ }^{1}$, Andra Leskovec ${ }^{2}$, Eva Ruzic-Sabljic ${ }^{3}$, Maja Arnez ${ }^{1, *}$ \\ ${ }^{1}$ University Medical Center Ljubljana, Faculty of Medicine University of Ljubljana, Ljubljana, Slovenia \\ ${ }^{2}$ Community Health Center Idrija, Idrija, Slovenia \\ ${ }^{3}$ Institute of Microbiology and Immunology, Faculty of Medicine University of Ljubljana, Ljubljana, Slovenia
}

\section{Email address:}

mojca.rozic@kclj.si (M. Rozic), andra.leskovec@gmail.com (A. Leskovec), eva.ruzic-sabljic@mf.uni-lj.si (E. Ruzic-Sabljic), maja.arnez@kclj.si (M. Arnez)

${ }^{*}$ Corresponding author

\section{To cite this article:}

Mojca Rozic, Andra Leskovec, Eva Ruzic-Sabljic, Maja Arnez. Lyme Meningitis in Children with Acute Serous Meningitis with no Clinical Signs of Lyme Borreliosis at Presentation. American Journal of Pediatrics. Vol. 5, No. 4, 2019, pp. 246-253.

doi: 10.11648/j.ajp.20190504.24

Received: October 18, 2019; Accepted: November 5, 2019; Published: November 11, 2019

\begin{abstract}
We evaluate the incidence of Lyme meningitis (LM) in children with acute serous meningitis and compare demographic, clinical and laboratory findings in children with LM and non-LM. During 2004-2005, 122 children fulfilled the inclusion criteria for this prospective clinical study (age $<15$ years, meningitis, without typical clinical sign for Lyme borreliosis on admission). Antibodies to $B$. burgdorferi sensu lato were determined in blood and cerebrospinal fluid (CSF) and isolation of $B$. burgdorferi sensu lato was performed. LM was confirmed by isolation of $B$. burgdorferi sensu lato from blood and/or CSF and/or seroconversion to borrelial antigens and/or demonstration of borrelial intrathecal antibody production and/or history of erythema migrans. LM was probable in patients with positive but unchanging borrelial serum antibody titers. LM $(83 \%$ confirmed, $17 \%$ probable) was established in 41 (34\%) patients. Demographic, clinical and neurologic findings were comparable between the two groups. Fever and peripheral leukocytosis were more common in non-LM and inappetence and lymphocytic pleocytosis in LM. Borrelial serum IgM and/or IgG was found in $25 \%$, seroconversion in $39 \%$, IgG intrathecal antibody production in 5\% and isolation of B. burgdorferi sensu lato from CSF and blood in $41 \%$ and $22 \%$ of patients, respectively. LM was found in $34 \%$ of children with acute serous meningitis. It is impossible to distinguish LM from non-LM only from medical history, clinical examination and basic blood and CSF investigations. For this reason, other signs of Lyme borreliosis and microbiological studies on Lyme borreliosis are compulsory.
\end{abstract}

Keywords: Lyme Meningitis, Children, Lyme Borreliosis, Diagnosis

\section{Introduction}

Lyme borreliosis (LB) is a tick-borne infectious disease caused by Borrelia burgdorferi sensu lato. The principal vectors of LB are Ixodes scapularis in the United States of America (USA) and Ixodes ricinus in Europe. In USA, the only species known to cause LB is B. burgdorferi sensu stricto (B. burgdorferi) while in Europe at least five species can cause human disease from which $B$. afzelii and B. garinii are predominant. B. afzelii is mostly associated with a skin lesion known as erythema migrans (EM), which is pathognomonic clinical sign of LB, while $B$. garinii seems to be most neurotropic [1-3].
LB appears in three stages: early localized, early disseminated and late LB [1-3]. Acute serous meningitis is a part of early, disseminated stage of the disease [4, 5]. Diagnosis of LM can be simple if associated clinical signs of LB (EM, cranial nerve involvement, borrelial lymphocytoma, radiculitis, etc.) are clearly evident. Differentiating Lyme meningitis (LM) from other forms of acute serous meningitis in children is a common diagnostic dilemma in LB endemic regions [6-9]. The vast majority of cases in children are due to enteroviral infection [10]. Parenteral antibiotics are indicated in children for LM but not when causes of acute serous meningitis are viral [11].

This prospective clinical study was performed to evaluate 
the incidence of LM in children with acute serous meningitis and to compare demographic, clinical and laboratory findings in children with LM and non-LM.

\section{Patients and Methods}

\subsection{Patients and Study Design}

The prospective clinical study was conducted at the Department of Infectious Diseases, University medical Centre Ljubljana, Slovenia in 2004 and 2005. The study was approved by the Medical Ethics Committee of the Ministry of Health of the Republic of Slovenia. Informed consent was obtained from parents of all patients. Our patients were consecutive children younger than 15 years, hospitalized because of acute serous meningitis, without EM or other highly suggestive clinical sign of LB (cranial nerve involvement, borrelial lymphocytoma, radiculitis etc.). The patients were followed-up for at least 12 months.

\subsection{Methods}

Medical history, physical examination, basic hematologic, biochemical and microbiologic investigations, and lumbar puncture with cerebrospinal fluid (CFS) investigation were performed at the time of admission. Abnormal CSF findings were defined as reported previously in our study of patients with multiple EM and central nervous system (CNS) involvement [12]. Briefly, a white blood cell count (WBC) $\geq$ $5 \times 10^{6} / 1$ in CSF was considered as CSF pleocytosis, elevated protein level $\geq 0.45 \mathrm{~g} / \mathrm{l}$, albumin $\geq 300 \mathrm{mg} / 1, \mathrm{IgG} \geq 40 \mathrm{mg} / \mathrm{l}$, $\mathrm{IgM} \geq 0.7 \mathrm{mg} / \mathrm{l}, \quad \mathrm{IgA} \geq 5 \mathrm{mg} / 1$ and decreased glucose concentrations $<50 \%$ of blood glucose. CSF flow rate and the presence of intrathecal antibody production were defined according to the criteria reported by Reiber et al [13]. In each patient venous blood and CSF samples were simultaneously taken for determination of CSF flow rate. In blood and CSF concentrations of albumin and immunoglobulins: $\mathrm{G}$ (IgG), A $(\operatorname{Ig} \mathrm{A})$ and $\mathrm{M}(\operatorname{IgM})$ were determined.

\subsection{Microbiologic Investigations}

Borrelial immunofluorescent assay (IFA) of IgM and IgG antibody titres without preabsorbtion were determined in serum and CSF as reported previously [14]. Titers $\geq 256$ in serum and $\geq 16$ in CSF were considered positive. Intrathecal specific antibody synthesis was determined by calculation of antibody index (AI). AI > 1.4 was considered as increased [13]. Borrelial serum antibodies measurements were repeated $1,3,6$ and 12 months after the enrolment into the study.

Blood and CSF specimens were cultured in modified Kelly-Pettenkofer (MKP) medium. Specimens were incubated at $33^{\circ} \mathrm{C}$ and examined by dark-field microscopy. Isolated strains of $B$. burgdorferi sensu lato were identified by polymerase chain reaction (PCR) and/or by pulsed-field gel electrophoresis (PFGE) as reported previously [15-17]. DNA was restricted by $M l u \mathrm{I}$ restriction enzyme.

The diagnosis of LB was established according to the case definitions used in our previous studies [18]. Briefly, LB was considered confirmed by isolation of $B$. burgdorferi sensu lato from blood and/or CSF and/or by seroconversion to borrelial antigens and/or by demonstration of borrelial intrathecal antibody production and/or EM four months prior to the onset of meningitis. LB was considered probable in patients with positive but unchanging borrelial serum antibody titers.

\subsection{Treatment}

Patients with LM were treated with intravenous ceftriaxone for 14 days.

\subsection{Statistical Analysis}

Differences in categoric data were analyzed by the Yates corrected chi square test or Fisher's exact test, whereas differences in continuous data were assessed by KruskalWallis test and Wilcoxon rank sum test. All $\mathrm{P}$ values were two tailed; $\mathrm{P}<0.05$ was considered statistically significant.

\section{Results}

During the two-year period 122 patients (36 girls, 86 boys) fulfilled the inclusion criteria. The median age of the patients was 7.0 years (range: 2.5 to 14.5 ). There was no difference in age regarding sex of the patients: median age in girls was 6.75 $(3-14.5)$ years and in boys $7.5(2.5-14.5)$ years $(p=0.1290)$. Median duration of hospitalization was $4(2-18)$ days.

According to the case definitions, the diagnosis of LM was established in 41 (34\%) out of 122 patients with acute serous meningitis. LM was confirmed in $34(83 \%)$ and probable in 7 (17\%) patients (Table 1 ).

Table 1. Case definitions for the diagnosis of Lyme meningitis in 41 patients with acute serous meningitis.

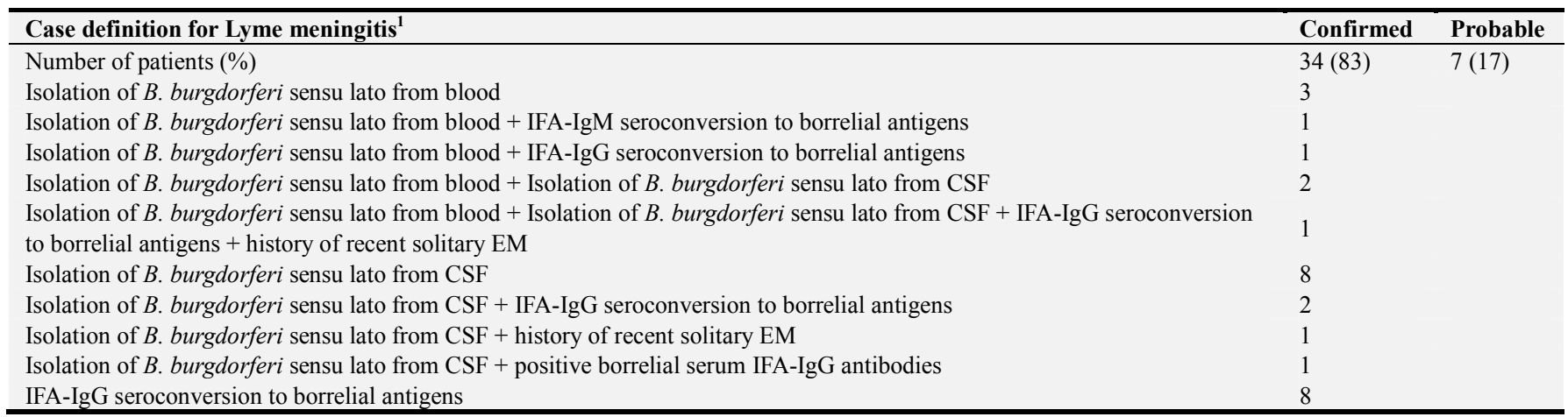




\begin{tabular}{|c|c|c|}
\hline Case definition for Lyme meningitis ${ }^{1}$ & Confirmed & Probable \\
\hline IFA-IgM seroconversion to borrelial antigens & 2 & \\
\hline IFA-IgG seroconversion to borrelial antigens + history of recent solitary EM & 1 & \\
\hline History of recent solitary EM & 1 & \\
\hline $\begin{array}{l}\text { Positive borrelial serum IFA-IgG antibodies + borrelial intrathecal IFA-IgG antibody production }(\mathrm{AI}=7.6)+\text { history of recent } \\
\text { multiple EM }\end{array}$ & 1 & \\
\hline Positive borrelial serum IFA-IgG antibodies + borrelial intrathecal IFA-IgG antibody production $(\mathrm{AI}=29.79)$ & 1 & \\
\hline Positive borrelial serum IFA-IgG antibodies & & 5 \\
\hline Positive borrelial serum IFA-IgM antibodies & & 2 \\
\hline
\end{tabular}

${ }^{1}=$ reference 18

IFA $=$ Immunofluorescent assay

$\mathrm{CSF}=$ cerebrospinal fluid

$\mathrm{EM}=$ erythema migrans

$\mathrm{AI}=$ antibody index $(\leq 1.4$ normal value $)$

The month of the hospitalization in patients with LM and non-LM is shown in figure 1.

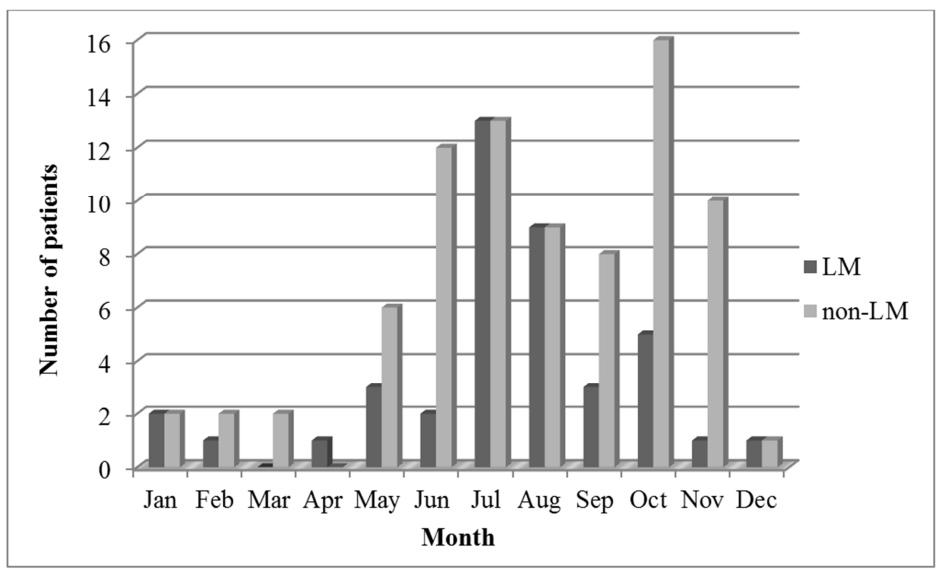

Figure 1. Month of hospitalization in 41 patients with Lyme meningitis (LM) and 81 patients with non-Lyme meningitis (non-LM).

Demographic features and clinical characteristics in the two groups are shown in table 2. The duration of illness before the hospitalization was longer in patients with LM but the difference was not statistically significant.

Table 2. Demographic and clinical features in 41 patients with Lyme meningitis (LM) and 81 with non-Lyme meningitis (non-LM).

\begin{tabular}{|c|c|c|c|}
\hline Variable & $\mathbf{L M}$ & Non-LM & $\mathbf{P}$ \\
\hline Female $^{1}$ & $16(39)$ & $20(25)$ & 0.1529 \\
\hline Male $^{1}$ & $25(61)$ & $61(75)$ & \\
\hline \multicolumn{4}{|l|}{ Age (years): } \\
\hline Median (range) & $7(2.5-14.5)$ & $7.5(3-14.5)$ & \\
\hline Tick bite $^{1}$ & $22(54)$ & $35(43)$ & 0.3678 \\
\hline \multicolumn{4}{|l|}{ Incubation (days) ${ }^{2}$} \\
\hline Median (range) & $16(6-79)$ & $19(3-60)$ & \\
\hline Biphasic course of the illness ${ }^{1}$ & $16(39)$ & $35(43)$ & 0.8038 \\
\hline \multicolumn{4}{|l|}{ Duration of the illness ${ }^{3}$} \\
\hline Mean \pm SD & $16.3 \pm 34.9$ & $6.4 \pm 6.4$ & 0.0742 \\
\hline Median (range) & $7(1-180)$ & $4(0-25)$ & \\
\hline Duration from the second phase ${ }^{3}$ & $10.8 \pm 37.2$ & $1.9 \pm 1.8$ & 0.6319 \\
\hline Median (range) & $1(0-150)$ & $1(0-8)$ & \\
\hline \multicolumn{4}{|c|}{ Interval between the onset of the initial and the second phase of the illness (days) } \\
\hline Median (range) & $6(2-30)$ & $9(2-22)$ & \\
\hline Antibiotics used prior the hospitalization ${ }^{1}$ & $9(22)$ & $18(22)$ & 0.8440 \\
\hline \multicolumn{4}{|l|}{ Duration of hospitalization (days) } \\
\hline Mean \pm SD & $4.8 \pm 1.7$ & $5.2 \pm 2.8$ & 0.8682 \\
\hline Median (range) & $4(3-9)$ & $4(2-18)$ & \\
\hline
\end{tabular}

${ }^{1}$ Number of patients (\%)

${ }^{2} 14$ patients with LM, 22 patients with non-LM

${ }^{3}$ Days prior to the hospitalization 
At the time of admission to the hospital fever was more common in non-LM $(p=0.0030)$ and inappetence in LM $(p=$ $0.0073)$. Five $(12 \%)$ patients with LM had had history of untreated EM from seven days to two months prior to the inclusion into the study. On physical examination, no difference in clinical and neurologic signs between the patients with LM and non-LM were found. Patients with LM had significantly milder illness than patients with non-LM (Table 3).

Table 3. Clinical and neurologic symptoms and signs in 41 patients with Lyme meningitis (LM) and 81 with non-Lyme meningitis (non-LM).

\begin{tabular}{|c|c|c|c|}
\hline Symptom $^{1}$ & LM & Non-LM & $\mathbf{P}$ \\
\hline Headache & $36(88)$ & $72(89)$ & 1.0000 \\
\hline Fever & $25(61)$ & $70(86)$ & 0.0030 \\
\hline Vomiting & $25(61)$ & $58(72)$ & 0.3253 \\
\hline Fatigue & $11(27)$ & $22(27)$ & 0.8596 \\
\hline Photophobia & $8(20)$ & $16(20)$ & 0.8341 \\
\hline Inappetence & $10(24)$ & $5(6)$ & 0.0093 \\
\hline Nausea & $6(15)$ & $13(16)$ & 0.9516 \\
\hline Abdominal pain & $3(7)$ & $18(22)$ & 0.0708 \\
\hline Neck pain & $7(17)$ & $8(10)$ & 0.3944 \\
\hline Myalgia & $5(12)$ & $5(6)$ & 0.3012 \\
\hline Arthralgia & $5(12)$ & $7(9)$ & 0.5348 \\
\hline Skeletal pain & $2(5)$ & $1(1)$ & 0.2611 \\
\hline Rigor & 0 & $4(5)$ & 0.2993 \\
\hline Diarrhoea & $3(7)$ & $6(7)$ & 1.0000 \\
\hline Sore throat & 0 & $5(6)$ & 0.1668 \\
\hline Common cold & $4(10)$ & $6(7)$ & 0.7311 \\
\hline Cough & $4(10)$ & $8(10)$ & 1.0000 \\
\hline Earache & $1(2)$ & $2(2)$ & 1.0000 \\
\hline Dizziness & $1(2)$ & $2(2)$ & 1.0000 \\
\hline Irritability & $1(2)$ & $1(1)$ & 1.0000 \\
\hline Skin rash & $1(2)$ & $2(2)$ & 1.0000 \\
\hline Consciousness disturbance & $1(2)$ & $2(2)$ & 1.0000 \\
\hline Convulsions & 0 & $2(2)$ & 0.5501 \\
\hline Collapse & 0 & $2(2)$ & 0.5501 \\
\hline Aphasia & 0 & $1(1)$ & 1.0000 \\
\hline Palpitation & $1(2)$ & 0 & 0.3361 \\
\hline Sternal pain & 0 & $1(1)$ & 1.0000 \\
\hline \multicolumn{4}{|l|}{ Clinical sign ${ }^{1}$} \\
\hline Temperature $\geq 38^{\circ} \mathrm{C}$ & $13(32)$ & $37(46)$ & 0.1980 \\
\hline Erythematous throat & $11(27)$ & $20(25)$ & 0.9712 \\
\hline Dehydration & $4(10)$ & $20(25)$ & 0.0856 \\
\hline Abdominal tenderness & $5(12)$ & $5(6)$ & 0.3012 \\
\hline Skin rash & $2(5)$ & $8(10)$ & 0.4925 \\
\hline Cardiac murmur & $5(12)$ & $4(5)$ & 0.1617 \\
\hline Conjunctivitis & $4(10)$ & $3(4)$ & 0.2229 \\
\hline Otitis & $2(5)$ & $2(2)$ & 0.6017 \\
\hline Rhinitis & $1(2)$ & $2(2)$ & 1.0000 \\
\hline Bronchitis & $1(2)$ & $2(2)$ & 1.0000 \\
\hline Enlarged liver & 0 & $6(7)$ & 0.0964 \\
\hline \multicolumn{4}{|l|}{ Neurologic sign ${ }^{1}$} \\
\hline Positive meningeal signs & $35(85)$ & $70(86)$ & 0.9061 \\
\hline Tremor & $5(12)$ & $10(12)$ & 0.7888 \\
\hline Ataxia & $1(2)$ & $1(1)$ & 1.0000 \\
\hline Conscious disturbance & 0 & $4(5)$ & 0.2993 \\
\hline Reduced muscle strength & 0 & $1(1)$ & 1.0000 \\
\hline Elevated muscle tone & 0 & $2(2)$ & 0.5501 \\
\hline Hyperreflexia & 0 & $2(2)$ & 0.5501 \\
\hline Babinski's sign & 0 & $2(2)$ & 0.5501 \\
\hline \multicolumn{4}{|l|}{ Severity of initial illness ${ }^{2}$} \\
\hline Mild & $34(83)$ & $51(63)$ & 0.0396 \\
\hline Moderate & $7(17)$ & $29(36)$ & 0.0533 \\
\hline Severe & 0 & $1(1)$ & 1.0000 \\
\hline
\end{tabular}

${ }^{1}$ Number of patients (\%)

${ }^{2}$ Mild $=$ meningitis, Moderate $=$ meningoencephalitis, Severe $=$ treatment in intensive care unit

Higher frequency of leukocytosis [57/81 (70\%) versus 20/41 (49\%); $p=0.0327]$ with neutrophil predominance [73/81 (91\%) versus 30/41 (73\%); $p=0.0175]$ was detected in patients with non-LM. No other significant difference regarding basic hematologic and biochemical investigations were found between the two groups. 
Blood for culturing for B. burgdorferi sensu lato was taken from 110/122 (90\%) patients with acute serous meningitis: in $37(90 \%)$ with LM and $73(90 \%)$ with non-LM (p = 1.0000). The overall isolation rate of $B$. burgdorferi sensu lato $(B$. afzelii 3, B. garinii 1, Borreliae did not grow well enough to enable identification of the genospecies 4) from blood in patients with LM was $22 \%$ (8/37).

At the time of admission to the hospital, borrelial serum IFA IgM and IgG were determined in all 41 patients with LM and $79(98 \%)$ with non-LM ( $=1.0000)$. Positive IgM and IgG antibodies against $B$. burgdorferi sensu lato were found in $2(5 \%)$ and $8(20 \%)$ patients with LM, respectively. We couldn't find any patient with simultaneous presence of specific serum IgM and IgG. Seroconversion to borrelial antigens was detected in 16/41 (39\%) patients.

At the time of inclusion into the study lumbar puncture and CSF investigation were performed in all patients. Time interval between the beginning of illness and lumbar puncture was comparable between the two groups [7 $(1-180)$ days in LM versus $4(0-26)$ in non-LM, p= $0.0674]$.

CSF findings in 122 patients with acute serous meningitis are shown in table 4. Lymphocytic predominance was more frequently found in patients with LM.

Table 4. Cerebrospinal fluid findings in 41 patients with Lyme meningitis (LM) and 81 with non-Lyme meningitis (non-LM).

\begin{tabular}{|c|c|c|c|}
\hline Variable & LM & Non-LM & $\mathbf{P}$ \\
\hline \multicolumn{4}{|l|}{ White blood cell count $\times 10^{6} / 1$} \\
\hline Mean $\pm \mathrm{SD}$ & $296.7 \pm 445.8$ & $235 \pm 329.4$ & 0.8901 \\
\hline Median (range) & $123(8-1877)$ & $133(6-2048)$ & \\
\hline Lymphocytic predominance $^{1}$ & $29(71)$ & $35(43)$ & 0.0073 \\
\hline \multicolumn{4}{|c|}{ Number of abnormal findings/number of examined patients $(\%)$} \\
\hline Decreased glucose concentration $^{2}$ & $10 / 40(25)$ & 9/81 (11) & 0.0873 \\
\hline Elevated total protein concentration $(\geq 0.45 \mathrm{mg} / \mathrm{L})$ & $15 / 40(38)$ & $39 / 81(48)$ & 0.3607 \\
\hline Elevated albumin concentration $(\geq 300 \mathrm{mg} / \mathrm{L})$ & $12 / 37(32)$ & $22 / 68(32)$ & 0.8337 \\
\hline Elevated total $\mathrm{IgG}$ concentration $(\geq 40 \mathrm{mg} / \mathrm{L})$ & $11 / 37(30)$ & $18 / 68(26)$ & 0.8979 \\
\hline Elevated total $\mathrm{IgA}$ concentration $(\geq 5 \mathrm{mg} / \mathrm{L})$ & $7 / 37(19)$ & $10 / 68(15)$ & 0.7775 \\
\hline Elevated total $\mathrm{IgM}$ concentration $(\geq 0.7 \mathrm{mg} / \mathrm{L})$ & $28 / 37(76)$ & $51 / 66(77)$ & 0.9530 \\
\hline
\end{tabular}

${ }^{1}$ Number of patients (\%)

${ }^{2}<50 \%$ of blood glucose

$\mathrm{Ig}=$ Immunoglobulins

In $8 / 122(7 \%)$ patients (all were boys) more than $1000 \mathrm{x}$ $10^{6} / 1 \mathrm{WBC}$ were found in CSF: in $4(10 \%)$ with LM and 4 $(5 \%)$ with non-LM $(\mathrm{p}=0.4310)$.

In 109/122 (89\%) patients CSF was taken for culturing for B. burgdorferi sensu lato: in $37(90 \%)$ patients with LM and $72(88 \%)$ in non-LM. The overall isolation rate of $B$. burgdorferi sensu lato (B. afzelii 6, B. garinii 6, Borreliae did not grow well enough to enable identification of the genospecies 3) from CSF in patients with LM was $41 \%$ $(15 / 37)$. In $8 \%(3 / 37) B$. burgdorferi sensu lato was isolated simultaneously from blood and CSF.

At the time of inclusion into the study borrelial CSF IFA IgM and IgG were determined in 109/122 (89\%) patients: 39 $(95 \%)$ in LM and $70(86 \%)$ in non-LM $(\mathrm{p}=1.0000)$. Positive CSF IgG antibodies against B. burgdorferi sensu lato were found in $2(5 \%)$ patients with LM. In these patients intrathecal borrelial IgG synthesis was also established. We couldn't find any patients with LM and positive borrelial IgM in CSF.

\section{Discussion}

In the present study we were interested in the incidence of LM in Slovenian children with acute serous meningitis without EM or other highly suggestive clinical sign of LB. To our knowledge this is the first prospective study about this problem reported in the literature. In two years, we treated 122 children for acute serous meningitis. Using case definitions for the diagnosis of LB, LM was established in 41
(34\%) of patients (Table 1). Acute serous meningitis in children is mainly of enteroviral origin [10]. Because LM and enteroviral meningitis are common in LB-endemic regions and both occur mostly in the summer and fall, it is essential to differentiate clinical and laboratory features when EM is absent $[19,20]$. The treatment of viral meningitis is supportive only, whereas the treatment of LM with parenteral antibiotics significantly decreases both the acute and the long-term symptoms $[11,21]$.

In Norway, most children with neuroborreliosis are diagnosed between June and November, whereas no children are diagnosed between January and March [22]. The results of our study partially support this finding. The majority of our patients with LM were registered during the warm months. The numbers of hospitalized children with LM and non-LM were comparable, however patients with LM and non-LM were seen throughout the whole year (Figure 1).

The nervous system is involved in $10 \%$ to $15 \%$ of patients with untreated B. burgdorferi sensu lato infection [20]. Neurologic involvement in LB in children is most commonly seen as lymphocytic meningitis, with or without cranial nerve palsy $[20,23,24]$.

Retrospective studies from Europe and the USA report less pronounced signs and symptoms (fever, headache, neck stiffness) of meningitis, longer duration of symptoms before evaluation, lymphocytic pleocytosis and elevated CSF protein levels more often in LM than in non-LM patients [6, 11, 25, 26]. However, reported patients also exhibit papilledema, EM rash or cranial neuropathy that are typical 
or highly suggestive clinical signs for LB in up to $88 \%$ [6, 11, 19, 25-31].

In our previous prospective study on etiology and principal clinical features of acute serous meningitis in children conducted in 1997, the diagnosis of LM was based only on findings of $B$. burgdorferi sensu lato $\operatorname{IgM}$ and/or $\operatorname{IgG}$ antibodies in patient's blood $\left(16^{\text {th }}\right.$ annual meeting of the European Society for Paediatric Infectious Diseases, abstract P 92). LM was diagnosed in $4.9 \%$ out of 102 patients. The majority of patients with established etiology had enteroviral meningitis $(46.1 \%)$.

In present study we didn't search for enteroviral infection. LM was established in $34 \%$ out of 122 patients with acute serous meningitis. We believe that the higher percentage of patients with LM is partially the result of different diagnostic approach, using not only measurement of specific borrelial antibodies in blood but also in CSF, as well as with culturing of blood and CSF for B. burgdorferi sensu lato. Our patients had no EM or other typical or highly suggestive clinical sign of LB. For this reason, a direct comparison of demographic, clinical and laboratory characteristics of patients between studies reported in the literature is ambiguous. In our patients the duration of illness prior to the hospitalization was longer in patients with LM compared to those with non-LM, but the difference was not statistically significant (Table 2). At the time of admission to the hospital, fever was more common in non-LM and inappetence in LM, however headache, neck pain and fatigue were comparable between the two groups (Tables 3). On physical examination no significant difference in clinical and neurologic signs was found between the two groups (Table 3).

We agree with Porwancher that the most difficult problem with identifying patients with LM without EM is the need to rely on laboratory criteria for diagnosis of LB [27].

The diagnosis of LB is based on clinical manifestations and history of exposure to ticks in an endemic area [1-3]. Detection of borrelial antibodies represents a fundamental aid to diagnosis. Because neurologic symptoms, by definition, require disseminated infection, serologic tests are markedly positive, often with a prominent IgM component. Very rarely, neurologic symptoms proceed to development of a measurable antibody response so that convalescent serologic tests may be necessary [20].

At the time of admission to the hospital positive borrelial $\operatorname{IgM}$ and $\operatorname{IgG}$ antibodies were found in $5 \%$ and $20 \%$ of our patients with LM, respectively. Seropositivity was lower than reported in the literature $[1-3,32]$. The reason may be using a less sensitive diagnostic serological method [33]. Seroconversion to borrelial antigens was detected in 39\%.

Although not standardized, the most widely accepted laboratory method for diagnosis of acute neuroborreliosis is intrathecal antibody production to B. burgdorferi sensu lato $[23,25,27,34]$. Studies have shown variable sensitivity (33 - 92\%), but excellent specificity $(93-100 \%)$ for acute neuroborreliosis [27]. The detection of intrathecally produced IgM antibodies shows a high degree of sensitivity in neuroborreliosis with short duration of symptoms, especially in children [23, 32]. According to Christen in $10 \%$ of neuroborreliosis cases, the CSF is positive for borrelial $\operatorname{IgM}$ antibodies but serum is negative when tested first [35].

In our study, we couldn't find any child with $B$. burgdorferi sensu lato-IgM intrathecal antibody production. Borrelial IgG intrathecal antibody production was found in only 2 patients with LM (Table 1). This was expected since the median duration of illness before hospitalization in patients with LM was seven days (Table 2). Intrathecal antibody response to $B$. burgdorferi sensu lato usually begins in the second week after onset of neurologic symptoms [21].

Additional laboratory diagnostic method for LM is CSF culture for $B$. burgdorferi sensu lato. Although time consuming and relatively insensitive, it is still the gold standard for diagnosis of neuroborreliosis [27, 28, 36, 37]. Sensitivity is $10-30 \%$ : up to $50 \%$ in patients with disease duration of fewer than two weeks and $13 \%$ in patients with disease duration of greater than two weeks [32].

Our results support these findings since the median duration of illness in our patients with LM was seven days, and the rate of isolation of B. burgdorferi sensu lato from CSF was $41 \%$.

To our knowledge this is the first report on isolation of $B$. burgdorferi sensu lato from CSF in prospectively evaluated children with acute serous meningitis without EM or highly suggestive clinical sign of LB. There was no significant difference between isolation rate of B. garinii and B. afzelii. This is in contrast to the data from the literature regarding neuroborreliosis $[1-3,20]$. We couldn't find any patient with isolation of $B$. burgdorferi from CSF. This was expected since $B$. burgdorferi is infrequent pathogen of neuroborreliosis [20].

B. burgdorferi sensu lato typically elicits CSF pleocytosis, altered blood-brain barrier permeability, increased protein and often a local antibody response resulting in a relative increase in CSF Ig concentration [38]. We found the same changes in our patients. However, patients with LM differ significantly from those with non-LM only in lymphocytic predominance, which was more common in patients with LM. There were no other significant differences regarding CSF findings between the two groups (Table 4).

Hypoglycorrhachia in areas endemic for LB is suggestive for acute LM [23]. Decreased CSF glucose concentration in our patients with LM and those with non-LM was found in $25 \%$ and $11 \%$, respectively (Table 4 ). The difference was not statistically significant $(\mathrm{p}=0.0873)$, however the median concentration of CSF glucose concentration was significantly lower in patients with LM [2.95 (range 2.1 - 3.9) versus 3.1 (range $2.2-4.3$ ), $\mathrm{p}=0.0184$ ].

The proposed treatment of LM, among others, is ceftriaxone intravenously for two to four weeks [20]. In our present study we treated all patients with LM with intravenous ceftriaxone for 14 days.

\section{Conclusion}

Antibiotics are indicated in children for LM but not when 
causes of acute serous meningitis are viral. In this prospective clinical study LM was found in $34 \%$ of children with acute serous meningitis with no signs of LB at presentation. In $27 \%$ we diagnosed LM only by isolation of $B$. burgdorferi sensu lato from blood or CSF. Isolation rates of $B$. garinii and B. afzelii from CSF were comparable. It is impossible to distinguish LM from non-LM only from medical history, clinical examination and basic blood and CSF investigations. For this reason, other signs of LB and microbiological studies on LB are compulsory. We believe that the direct detection of B. burgdorferi sensu lato from CSF should become an integral part of routine diagnostic procedures in children with acute serous meningitis in endemic regions for LB. Adding direct detection to routine diagnostic procedures would rationalize the use of antibiotics in children with acute serous meningitis.

\section{References}

[1] Stanek G, Wormser GP, Gray J, Strle F (2012). Lyme borreliosis. Lancet 397, 461-473.

[2] Stanek G, Strle F (2018). Lyme borreliosis-from tick bite to diagnosis and treatment. FEMS Microbiol Rev 42, 233-258.

[3] Steere AC, Strle F, Wormser GP, Hu LT, Branda JA, Hovius JWR, et al (2017). Lyme borreliosis. Nat Rev Dis Primers.; 2: 16090. doi: $10.1038 /$ nrdp.2016.90.

[4] Sood SK (2015). Lyme disease in children. Infect Dis Clin N Am 29, 281-294.

[5] Shapiro E (2018). Lyme borreliosis in 2018. What is new (and what is not). JAMA 320, 635-636.

[6] Avery RA, Frank G, Glutting JJ, Eppes SC (2006). Prediction of Lyme meningitis in children from Lyme disease-endemic region: a logistic-regression model using history, physical, and laboratory findings. Pediatrics 117, e1-e7.

[7] Esposito S, Bosis S, Sabatini C, Tagliaferri L, Principi N (2013). Borrelia burgdorferi infection and Lyme disease in children. Intern J Infect Dis 17, e153-e158.

[8] Sanchez E, Vannier E, Wormser GP, Hu LT (2016). Diagnosis, treatment, and prevention of Lyme disease, Human granulocytic anaplasmosis, and Babesiosis. JAMA 315, $1767-$ 1777.

[9] Barstad B, Quarsten H, Tveitnes D, Noraas S, Ask IS, Saeed $\mathrm{M}$, et al (2018). Direct molecular detection and genotyping of Borrelia burgdorferi sensu lato in cerebrospinal fluid of children with Lyme neuroborreliosis. J Clin Microbiol 56: e01868-17. https://doi.org/10.1128/JCM.01868-17.

[10] Rothbart HA (1995). Enteroviral infections of the central nervous system. Clin Infect Dis 20, 971-981.

[11] Garro AC, Rutman M, Simonsen K, Jaeger JL, Chapin K, Lockhart G (2009). Prospective validation of a clinical prediction model of Lyme meningitis in children. Pediatrics 123, e829-e834.

[12] Arnež M, Pleterski-Rigler D, Ahčan J, Ružić-Sabljić E, Strle F (2001). Demographic features, clinical characteristics and laboratory findings in children with multiple erythema migrans in Slovenia. Wien Klin Wochenschr 113, 98-101.

[13] Reiber H, Peter JB (2001). Cerebrospinal fluid analysis: disease-related data patterns and evaluation programs. J Neurol Sci 184, 101-122.

[14] Wilske B, Schierz G, Preac-Mursic V, Weber K, Pfister HW, Einhaupl K (1984). Serological diagnosis of erythema migrans disease and related diseases. Infection 5, 331-335.

[15] Preac-Mursic V, Wilske B, Schierz G (1986). European Borrelia burgdorfei isolation from humans and ticks culture conditions and antibiotic susceptibility. Zentralbl Bakteriol Mikrobiol Hyg A 263, 112-118.

[16] Ružić-Sabljić E, Arnež M, Logar M, Maraspin V, LotričFurlan S, Cimperman J, et al (2005). Comparison of Borrelia burgdorferi sensu lato strains isolation from specimens obtained simultaneously from two different sites of infection in individual patients. J clin Microbiol 43, 2194-2200.

[17] Postic D, Assous MV, Grimont PA, Baranton G (1994). Diversity of Borrelia burgdorferi sensu lato evidenced by restriction fragment length polymorphism of $\operatorname{rrf}(5 \mathrm{~S})$-rrl (23S) intergenic spacer amplicon. Int J Syst Bacteriol 44, 743-752.

[18] Arnež M, Lužnik-Bufon T, Avšič-Županc T, Ružić-Sabljić E, Petrovec M, Lotrič-Furlan S, et al (2003). Causes of febrile illnesses after a tick-bite in Slovenian children. Pediatr Infect Dis J 22, 1078-1083.

[19] Shah SS, Zaoutis TE, Turnquist J, Hodinka RL, Coffin SE (2005). Early differentiation of Lyme from enteroviral meningitis. Pediatr Infect Dis J 24, 542-545.

[20] Halperin JJ (2015). Nervous system Lyme disease. Infect Dis Clin N Am 29, 241-253.

[21] Garro AC, Rutman MS, Simonsen K, Jaeger JL, Chapin K, Lockhart G (2011). Prevalence of Lyme meningitis in children with aseptic meningitis in a Lyme disease-endemic region. Pediatr Infect Dis J 30, 990-992.

[22] Øymar R, Tveitnes D (2009). Clinical characteristics of childhood Lyme neuroborreliosis in an endemic area of northern Europe. Scand J Infect Dis 41, 88-94.

[23] Dayan NE, Rubin LG, Di John DD, Sood SK (2004). Hypoglycorrachia in Lyme meningitis. Pediatr Infect Dis J 23, 370-371.

[24] Broekhuijsen-van Henten D, Braun KP, Wolfs TFW (2010). Clinical presentation of childhood neuroborreliosis; neurological examination may be normal. Arch Dis Child 95, 910-914.

[25] Eppes SC, Nelson DK, Lewis L, Klein JD (1999). Characterization of Lyme meningitis and comparison with viral meningitis in children. Pediatrics 103, 957-960.

[26] Tuerlinckx D, Bodart E, Garrino MG, de Bilderling G (2003). Clinical data and cerebrospinal fluid findings in Lyme meningitis versus aseptic meningitis. Eur J Pediatr 162, 150153.

[27] Porwancher R (2006). Predictive model of Lyme meningitis. Pediatrics 118, 438-439.

[28] Tveitnes D, Natås OB, Skadberg Ø, Øymar K (2012). Lyme meningitis, the major cause of childhood meningitis in an endemic area: a population based study. Arch Dis Child 97, 215-220. 
[29] Cohn KA, Thompson AD, Shah SS, Hines EM, Lyons TW, Welsh EJ, et al (2012). Validation of clinical prediction rule to distinguish Lyme meningitis from aseptic meningitis. Pediatrics 129, e46-e53.

[30] Tuerlinckx D, Bodart E, Jamart J, Glupczynski Y (2009). Prediction of Lyme meningitis based on a logistic regression model using clinical and cerebrospinal fluid analysis. Pediatr Infect Dis J 28, 394-397.

[31] Waespe N, Steffen I, Heininger U (2010). Etiology of aseptic meningitis, peripheral facial nerve palsy, and a combination of both in children. Pediatr Infect Dis J 29, 453-456.

[32] Wilske B, Fingerle V, Schulte-Spechtel V (2007). Microbiological and serological diagnosis of Lyme borreliosis. FEMS Immunol Med Microbiol 49, 13-21.

[33] Cerar T, Ruzic-Sabljic E, Cimperman J, Stle F (2006). Comparison of immunofluorescence assay (IFA) and LIAISON $^{\circledR}$ in patients with different clinical manifestations of Lyme borreliosis. Wien Klin Wochenschr 118, 686-690.
[34] Theel ES, Aguero-Rosenfeld ME, Pritt B, Adem PV, Wormser GP (2019). Limitations and confusing aspects of diagnostic testing for neurologic Lyme disease in the United States. J Clin Microbiol 57: e1406-18. https://doi.org/10.1128/JCM.01406-18.

[35] Christen HJ (1996). Lyme neuroborreliosis in children. Ann Med 28, 235-40.

[36] Aguero-Rosenfeld ME, Wang G, Schwartz I, Wormser GP (2005). Diagnosis of Lyme borreliosis. Clin Microbiol Rev 18, 484-509.

[37] Schutzer SE, Body BA, Boyle J, Branson BM, Dattwyler RJ, Fikrig E, et al (2019). Direct diagnostic tests for Lyme disease. Clin Infect Dis 68, 1052-1057.

[38] Halperin JJ (2002). Nervous system Lyme disease. Vector Borne Zoonotic Dis 2, 241-247. 